\title{
Gas Sensitivity and Morphologically Characterized of Nanostructure CdO Doped In2O3 Films Deposited by Pulsed Laser Deposition
}

\section{Ali Ahmad Yousif* and Mazin H Hasan}

Department of Physics, College of Education, University of Al-Mustansiriyah, Baghdad, Iraq

\begin{abstract}
In this work, films have been grown under various deposition conditions in order to understand the effect of processing on the film properties and to specify the optimum condition, different indium oxide $\left(\operatorname{In}_{2} \mathrm{O}_{3}\right)$ contents $(0$, $1 \%, 3 \%, 5 \%$ and $7 \%$ ) using double frequency pulse laser beam (Q-switching) Neodymium-yttrium aluminum garnet (Nd:YAG (wavelength $532 \mathrm{~nm}$ )), to deposit Cadmium Oxide: Indium oxide (CdO:In $\mathrm{O}_{3}$ ) films on Aluminum Oxide (sapphire $\alpha-\mathrm{Al}_{2} \mathrm{O}_{3}(006)$ ) and quartz substrates. The structural properties of samples were investigated by using of surface morphology of the deposits materials has been studied by using atomic force microscopy (AFM). The samples are displayed granular structure. It was found that the grain size decreases with increasing of doping concentration ratio, the smallest grain size equal to $(79.11 \mathrm{~nm})$ and $(82.99 \mathrm{~nm})$ were achieved at ratio of doping $(7 \%)$ for quartz and sapphire $\alpha-\mathrm{Al}_{2} \mathrm{O}_{3}$ substrate, respectively. The sensitivity of undoped and doped CdO samples toward Nitric dioxide $\left(\mathrm{NO}_{2}\right)$ gas in air ambient has been measured in the home building system. All samples were tested at mixing ratio ( $3 \% \mathrm{NO}_{2}$ :air). The optimal operating temperature is found to be $200-225^{\circ} \mathrm{C}$ for pure $\mathrm{CdO}$ and decreases to $175-200^{\circ} \mathrm{C}$ for samples. The maximum sensitivity is equal to (263.97\%) with response time (13.5 s) and recovery time (15.5 s) are achieved at $(3 \%)$ doping concentration level for sapphire $\alpha-\mathrm{Al}_{2} \mathrm{O}_{3}$ substrate.
\end{abstract}

Keywords: In doped CdO nanostructures; Pulsed laser deposition; Structure; Sensing properties

\section{Introduction}

The preparation of thin films of the size of a nanometer is important because of their potential applications in the various fields of science and technology, including the diverse fields of electronics, optics, space science, aircraft science, defense and other industries [13]. $\mathrm{CdO}$ is an n-type semiconductor with a rock-salt crystal structure (fcc) and possesses a direct band gap of $2.2 \mathrm{eV}$ [4]. Its high electrical conductivity and high optical transmittance in the visible region of solar spectrum along with a moderate reflective index make it useful for various applications, photodiodes, gas sensors, etc [5,6]. Undoped, monodoped and dual doped $\mathrm{CdO}$ thin films have been prepared by various techniques such as spray pyrolysis [7], dc magnetron reactive sputtering [8], sol-gel [9], mechanochemical method [10] etc. The temperature is an important parameter for gas sensing materials and designing of the sensor. A sufficient degree of crystallinity is required to attain the desired electronic properties necessary for gas sensor application. Gas sensors using transparent $\mathrm{CdO}$ semiconductors to detect different gases have been extensively reported [11-14].

Nitrogen dioxide $\left(\mathrm{NO}_{2}\right)$ is one of the main harmful gases, which provokes noxious effects on environment and human health. Resistivetype sensors based on metal-oxide semiconductors have been intensively studied in the last decades due to the low cost, technological simplicity, small size, and ease of handling. Besides, thin-film gas sensors show high performance features such as high stability and fast response [15-17]. Furthermore, the compatibility with micromachined structures allows sensor miniaturization, reduction of the production cost, and power consumption. In this work, nanostructure $\mathrm{CdO}$ thin films with different $\operatorname{In}_{2} \mathrm{O}_{3}$ contents $(0,1 \%, 3 \%, 5 \%$ and $7 \%)$ prepared by Pulsed Laser Deposition. The present work investigates the effect of doping on the nanostructure $\mathrm{CdO}$ thin films. Crystal structure and sizes were studied from Morphological. Gas sensing properties were studied using static gas sensing system. These nanostructures $\mathrm{CdO}$ thin films were tested for sensing different conventional gases and were observed to be most selective and $\mathrm{NO}_{2}$ at different operating temperature.

\section{Experiment}

CdO: In thin films were synthesized by pulsed laser deposition system using a second harmonic Nd:YAG laser. Thin films were grown in a vacuum chamber with background pressure of $\sim 1 \times 10^{-3}$ mbar. The Nd:YAG laser was operated at the wavelength of $(\lambda=533 \mathrm{~nm})$ with the repetition rate of $(10 \mathrm{~Hz})$ and pulse duration of $(7 \mathrm{~ns})$. The target to substrate distance was $(3 \mathrm{~cm})$. The morphological features and microstructures of the films were analyzed using Atomic Force Microscopy (AFM-Digital Instruments Nan Scope) working in tapping mode. The necessary parts are the $\mathrm{x} / \mathrm{y}$ and $\mathrm{z}$ piezo that are separately actuated by $\mathrm{x} / \mathrm{y}$ drive and $\mathrm{z}$-control with extreme precision, so atomic distances can be measured. A micro-fabricated cantilever with a sharp tip is deflected by features on a sample surface, much like in a photograph but on a much smaller scale. A laser beam reflects off the backside of the cantilever into a set of photodetectors, allowing the deflection to be measured and assembled into an image of the surface. In order to determine the sensitivity, response time and recovery time of the fabricated CdO: $\operatorname{In}_{2} \mathrm{O}_{3}$ gas sensor detector, suitable setup is prepared for this purpose. Cylindrical stainless steel test chamber of diameter $21 \mathrm{~cm}$ and of height $20 \mathrm{~cm}$. The effective volume of the chamber is $6923 \mathrm{cc}$; it has an inlet for allowing the tested gas to flow in and an air admittance valve to allow the flow of atmospheric air after evacuation. A multi pin feed through at the base of the chamber allows the electrical connections to be established to the heater, K-type

*Corresponding author: Ali Ahmad Yousif, Department of Physics, College of Education, University of Al-Mustansiriyah, Baghdad, Iraq, Tel: †+964 566 415; E-mail: aliyousif73@gmail.com

Received November 03, 2015; Accepted November 25, 2015; Published December 01, 2015

Citation: Yousif AA, Hasan MH (2015) Gas Sensitivity and Morphologically Characterized of Nanostructure $\mathrm{CdO}$ Doped $\mathrm{In}_{2} \mathrm{O}$ Films Deposited by Pulsed Laser Deposition. J Biosens Bioelectron 6: 192. doi:10.4172/2155-6210.1000192

Copyright: @ 2015 Yousif AA, et al. This is an open-access article distributed under the terms of the Creative Commons Attribution License, which permits unrestricted use, distribution, and reproduction in any medium, provided the original author and source are credited. 
Citation: Yousif AA, Hasan MH (2015) Gas Sensitivity and Morphologically Characterized of Nanostructure CdO Doped $\operatorname{In}_{2} \mathrm{O}_{3}$ Films Deposited by Pulsed Laser Deposition. J Biosens Bioelectron 6: 192. doi:10.4172/2155-6210.1000192

Page 2 of 7

thermocouple, and sensor electrodes. The heater consists of a hot plate and a K-type thermocouple inside the chamber in order to control the operating temperature of the sensor. A personal computer (PC) interfaced digital multimater model (UNI-T UT81B), and Laptop PC, is used to register the variation of the sensor current when exposed to air- $\mathrm{NO}_{2}$ gas mixing ratio. The mixing gas is fed by zero air and test gas through a flow meter and needle valve arrangement. The mixing gas is feeding through a tube over the sensor inside the test chamber to give the real sensitivity.

The characterization of gas sensing properties was performed according to the procedure described by Liewhiran et al. [18]. The sensitivity, $S$ is defined in the following as the resistance ratio $R_{g} /$ $R_{a}$ for the oxiding gas where $R_{a}$ is the resistance in dry air, and $R_{g}$ is the resistance in test gas. The response time, $T_{\text {res }}$ is defined as the time required until $90 \%$ of the response signal is reached. The recovery times, $T_{r e c}$ denotes the time needed until $90 \%$ of the original baseline signal is recovered.

\section{Results and Discussion}

\section{Atomic force microscopy (AFM)}

It is well known that the atomic force microscopy (AFM) is one of the effective ways for the surface analysis due to its high resolution and powerful analysis software. The nanostructure $\mathrm{CdO}$ and CdO:In thin films were morphologically characterized using Atomic Force Microscopy (AFM) technique, also the surface structure of a coating gains more and more importance. In the extreme case of thin films the surface roughness may be in the order of the film thickness and can influence all film properties such as mechanical, electrical, magnetically, gas sensor or optical properties [15].

Figures 1 and 2 shows the two and three-dimensional of the $\mathrm{CdO}$ and CdO: In thin films which deposit on quartz and sapphire $\alpha-\mathrm{Al}_{2} \mathrm{O}_{3}$ substrates with $(0 \%, 3 \%$ and $7 \%)$ Indium concentration deposited at room temperatures. An area of $\left(2.5 \times 2.5 \mu \mathrm{m}^{2}\right)$ has been used for
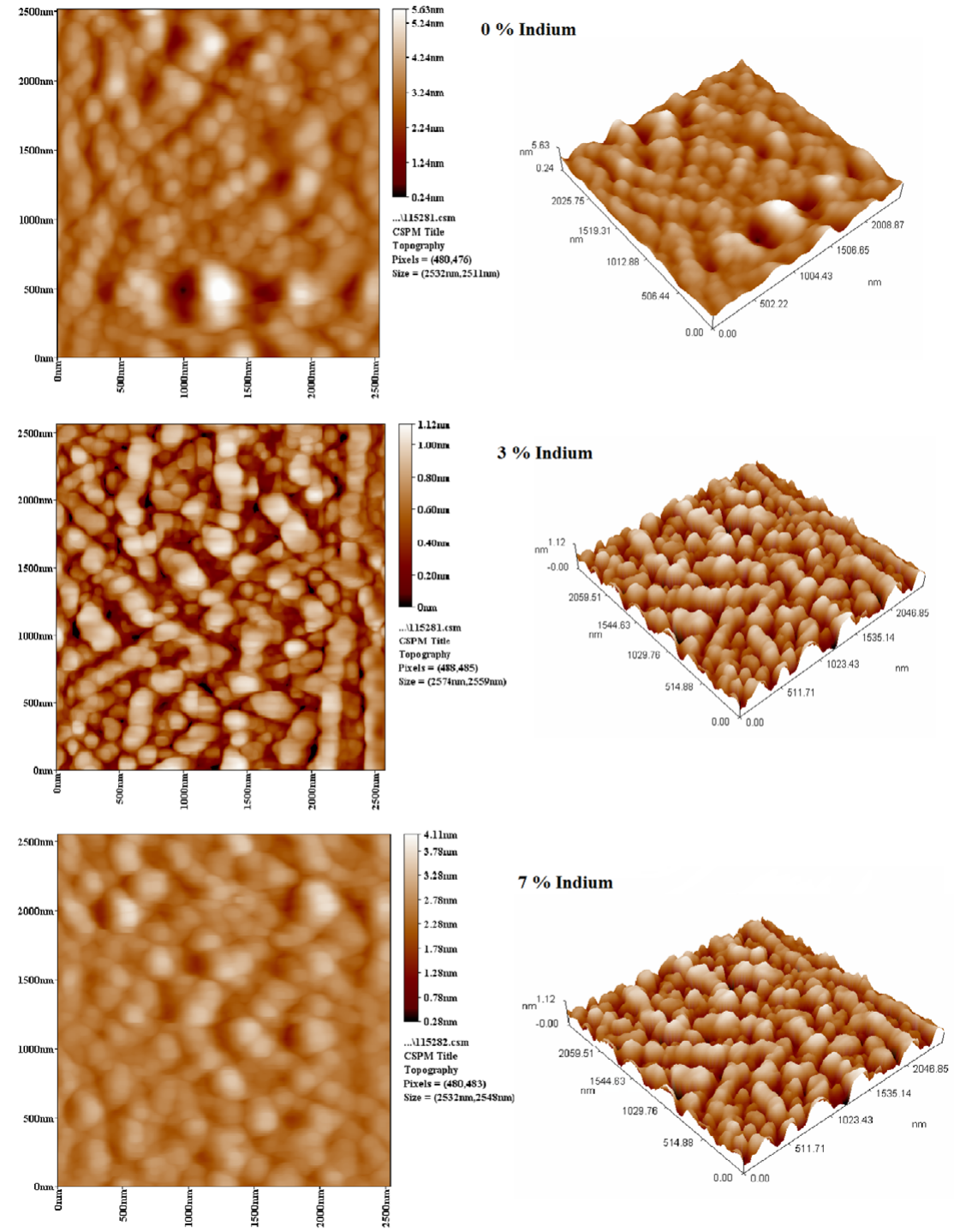

Figure 1: Two and three-D AFM images of pure $\mathrm{CdO}$ and $\mathrm{CdO}$ : In thin films at In concentration of $1 \%, 3 \%, 5$ and $7 \%$ for $\mathrm{Al}_{2} \mathrm{O}_{3}$ substrate. 
Citation: Yousif AA, Hasan MH (2015) Gas Sensitivity and Morphologically Characterized of Nanostructure CdO Doped $\mathrm{In}_{2} \mathrm{O}_{3}$ Films Deposited by Pulsed Laser Deposition. J Biosens Bioelectron 6: 192. doi:10.4172/2155-6210.1000192
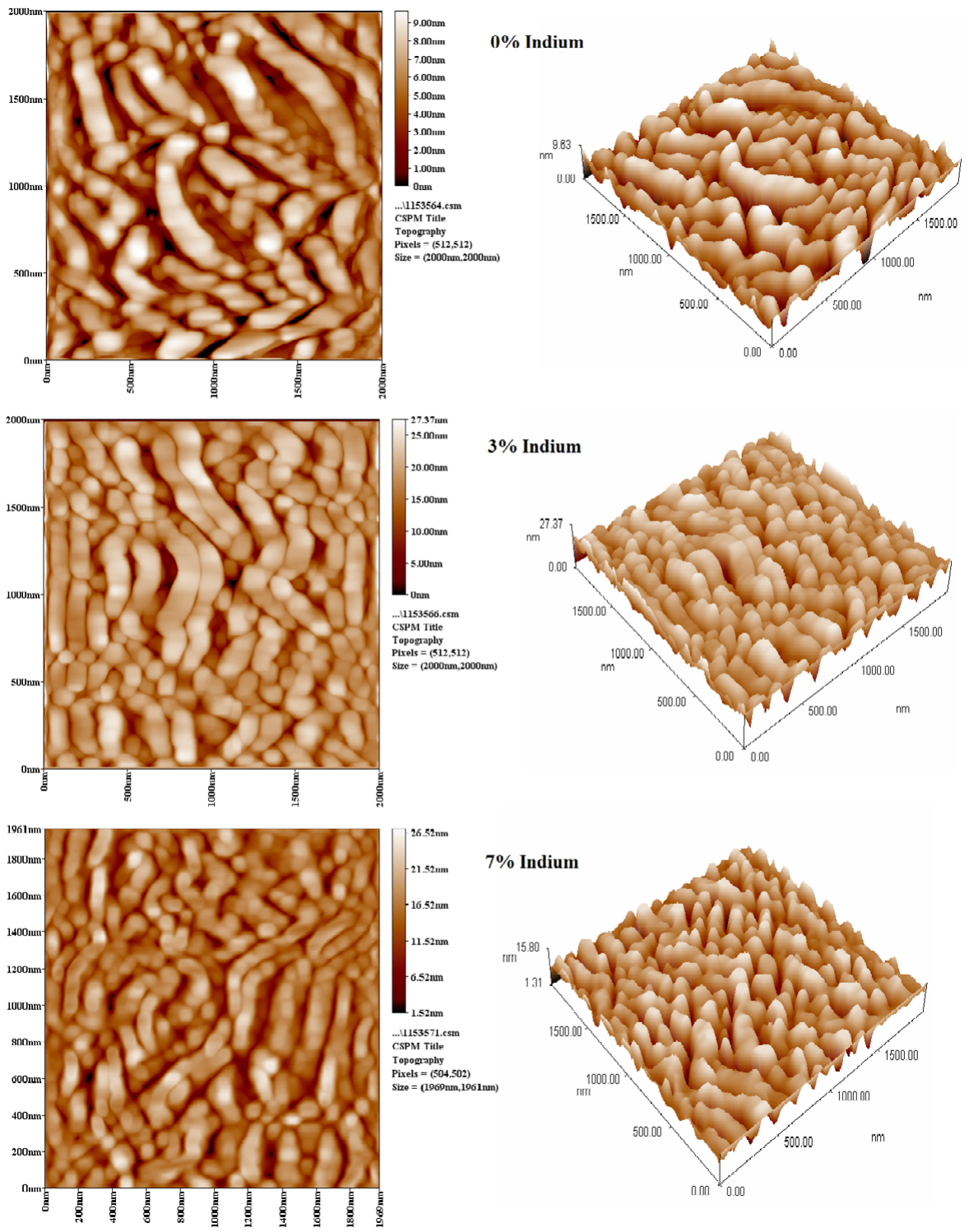

Figure 2: Two and three-D AFM images of pure $\mathrm{CdO}$ and $\mathrm{CdO}:$ In thin films at In concentration of $1 \%, 3 \%, 5$ and $7 \%$ for quartz substrate.

evaluation. It can be seen that films are uniform, densely packed and pinhole free, and it shows that the morphology of these films has smaller number of grain size and homogeneously distributed, which indicates the crystalline nature of the film. Initial visual investigations of the deposited films have shown that they are compact and have good adherence to the quartz and sapphire $\alpha-\mathrm{Al}_{2} \mathrm{O}_{3}$ substrates. No evidence of cracking, based on AFM image Figures 1 and 2 the grain density reduced indicating the smaller grains agglomerate together to form larger grains of $\mathrm{CdO}$ and $\mathrm{CdO}$ : In. On the other hand, the grain size surface roughness, Root Mean Square (RMS) and ten point heights of the films were measured using AFM technique as in Tables 1 and 2). The surface roughness defined as the standard deviation of the surface height profile from the average height is the most commonly reported measurement of surface roughness. The surface roughness is unavoidable since the grains are grown with different sizes. It can be seen that the surface roughness and RMS values decrease with increasing Indium ratio indicating for $\alpha-\mathrm{Al}_{2} \mathrm{O}_{3}$ substrate and increases with decreasing indium for quartz substrate as shown in Tables 1 and 2 .

The grains size is decreased with increasing of doping ratio from $46.93 \mathrm{~nm}$ for pure CdO to $39.55 \mathrm{~nm}$ for $7 \%$ doping for quartz substrate, while we note Average grain size increases with decreasing of doping ratio from $42.21 \mathrm{~nm}$ for pure $\mathrm{CdO}$ to $72.80 \mathrm{~nm}$ for $5 \%$ doping and return to decrease when increasing of doping ratio to $7 \%$ as shown in Tables 1 and 2.

The small spherical grains agglomerates are uniformly distributed of shape and size along the film surface, It can be seen that the film is crack-free and quite smooth with a decrease on the surface roughness [17], for sapphire $\mathrm{a}-\mathrm{Al}_{2} \mathrm{O}_{3}$ Smoothening of the films is possibly due to order of surface atoms to attain lower energy state. These films have a high grain density distribution with tightly packed grains. These films exhibits a lower surface roughness with uniform oriented This may correspond to the columnar structure which is associated with the (111) CdO textured growth [17]. 


\begin{tabular}{|l|c|c|c|c|}
\hline Samples & RMS [nm] & RS [nm] & Ten point height [nm] & Average G.S.[nm] \\
\hline CdO-Pure & 2.13 & 1.77 & 5.46 & 93.86 \\
\hline CdO:In 1\% & 2.71 & 2.18 & 9.29 & 90.44 \\
\hline CdO:In 3\% & 4.25 & 3.31 & 18.9 & 92.88 \\
\hline CdO:In 5\% & 5.26 & 4.13 & 17.6 & 82.69 \\
\hline CdO:In 7\% & 3.97 & 3.16 & 14.9 & 79.11 \\
\hline
\end{tabular}

Table 1: AFM characteristics of CdO:In thin films grown on quartz substrate.

\begin{tabular}{|l|c|c|c|c|}
\hline Samples & RMS [nm] & RS [nm] & Ten point height [nm] & Average G.S.[nm] \\
\hline CdO-Pure & 0.63 & 0.472 & 2.96 & 84.43 \\
\hline CdO:In 1\% & 0.228 & 0.186 & 0.696 & 101.34 \\
\hline CdO:In 3\% & 0.233 & 0.195 & 0.641 & 92.42 \\
\hline CdO:In 5\% & 0.238 & 0.196 & 0.621 & 145.61 \\
\hline CdO:In 7\% & 0.331 & 0.255 & 1.25 & 82.99 \\
\hline
\end{tabular}

Table 2: AFM characteristics of CdO:In thin films grown on sapphire( $\alpha$ $\mathrm{Al}_{2} \mathrm{O}_{3}$ ) substrate.

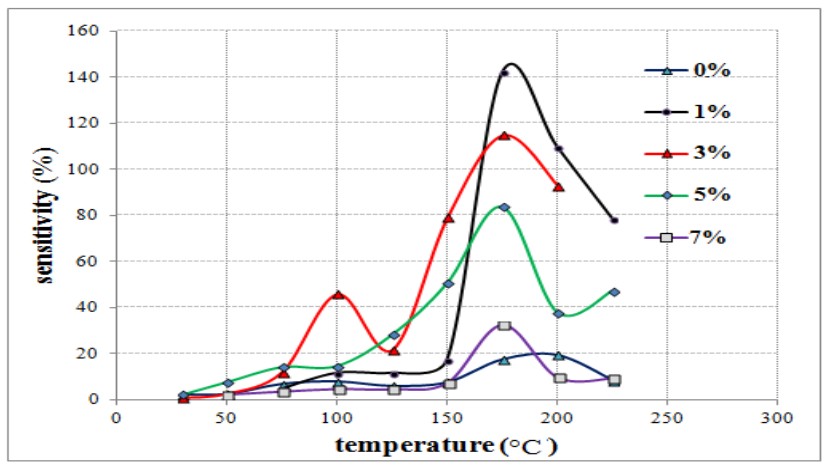

Figure 3: The variation of sensitivity with the operating temperature of the undoped and doped $\mathrm{CdO}$ (Pure, $1 \%, 3 \%, 5 \%, 7 \%)$, for mixing ratio $3 \%\left(\mathrm{NO}_{2}\right.$ : air), and bias voltage of $5 \mathrm{~V}$ on quartz substrate.

\section{Gas sensing measurement}

Determination of operation temperature of the sensor: One of the most important disadvantages of metal oxide gas sensors is the high temperature required for the sensor operation $\left(200-500^{\circ} \mathrm{C}\right)$. For this reason the effect of the operation temperature on thin films sensitivity is studied with the aim of optimizing of the operation temperature to the lowest possible value. The operating temperature is defined as the temperature at which the resistance of the sensor reaches a constant value. The changing of resistance is just only influenced by the presence of amount of some gases of interest [19].

Figures 3 and 4 shows the sensitivity as a function of operating temperature in the range $\left(25-225^{\circ} \mathrm{C}\right)$ for pure $\mathrm{CdO}$ and doping with different concentration of $\operatorname{In}_{2} \mathrm{O}_{3}$ which are deposited on quartz and a- $\mathrm{Al}_{2} \mathrm{O}_{3}$ substrates at $3 \% \mathrm{NO}_{2}$ :air mixing ratio the bias voltage of 5 Voltage were applied on the all samples. The gas sensitivity tests were performed at room temperature and increased to $225^{\circ} \mathrm{C}$ by $25^{\circ} \mathrm{C}$ step. Results show the increase in the operating temperature leads to an improvement of the films sensitivity. It is obvious in figures that the sensitivity of all films increases with increasing of the operating temperature. This is attributed to increase in the rate of surface reaction of the target gas.

Maximum peak values are seen at certain temperatures called optimal temperature and then decreases with further increase in temperature and explains why the correlations between sensitivity and temperature take a volcano shape for semiconductor metal oxide gas sensors [19]. At the optimal temperature, the activation energy may be enough to complete the chemical [20]. The optimal temperature is $200^{\circ} \mathrm{C}$ for pure $\mathrm{CdO}$, and it decreased to $175^{\circ} \mathrm{C}$ for Indium Oxide doping $\mathrm{CdO}$ for quartz substrate. This blue shift in the optimal temperature explains the occurrence of chemical reactivity at lower temperature. This decreased in temperature agrees with Ansari et al. [21]. They observed that increases and decrease in the sensitivity indicates the adsorption and desorption phenomenon of the gases. The optimal temperature is confirmed for each undoped and doped samples for two cycles. For $\mathrm{NO}_{2}$ gas, the sensitivity was observed to increase at operating temperature up to $100^{\circ} \mathrm{C}$. The higher sensitivity may be attributed to the optimum number of misfits on the surface, porosity, largest surface area and the larger rate of oxidation of $\mathrm{NO}_{2}$ at $175^{\circ} \mathrm{C}$ for film. The maximum sensitivity of the pure $\mathrm{CdO}$ film to $\mathrm{NO}_{2}$ gas are found to be $19.4 \%$ at $200^{\circ} \mathrm{C}$ for quartz substrate and $38.5 \%$ at $225^{\circ} \mathrm{C}$ for $\mathrm{a}-\mathrm{Al}_{2} \mathrm{O}_{3}$ substrate. The maximum sensitivity were found to be $142.1 \%$ at $1 \% \operatorname{In}_{2} \mathrm{O}_{3}$ doped for quartz substrate and $263.97 \%$ at $3 \% \operatorname{In}_{2} \mathrm{O}_{3}$ doped on $\alpha-\mathrm{Al}_{2} \mathrm{O}_{3}$ substrate observed at the optimal temperature is $175^{\circ} \mathrm{C}$ and then decrease with a further increase in operating temperature, At high temperature, the charge-carrier concentration increases and the Debye length decreases. This is one possible reason for the decreasing sensitivity at higher temperature [22]. The sensitivity as well as response time is temperature dependent since the chemical kinetics governing the solid-gas interface reaction is temperature dependent.

\section{Response time and recovery time}

Figures 5 and 6 shows the relation between the response time and the Recovery time with Indium Oxide doping ratio at optimum operating temperature $\left(175^{\circ} \mathrm{C}\right)$ of the undoped and doped $\mathrm{CdO}$ for $3 \% \mathrm{NO}_{2}$ :air and bias voltage of $5 \mathrm{~V}$ on quartz and sapphire $\alpha-\mathrm{Al}_{2} \mathrm{O}_{3}$ substrates.

The response speed is studied at the temperature at which the sensor exhibited a maximum sensitivity. The above figures shows that the (3\%) $\mathrm{In}_{2} \mathrm{O}_{3}$ doped samples exhibits a fast response speed (20.7 s), (13.5) and recovery time (45 s), (15.3) for quartz and $\mathrm{Al}_{2} \mathrm{O}_{3}$ substrate respectively. This revealed that a $(3 \%) \operatorname{In}_{2} \mathrm{O}_{3}$ doped quantity of impurities is the best doping ratio to achieve fast response sensor. The quick response sensor for $\mathrm{NO}_{2}$ gas may be due to faster oxidation of gas [23]. Indium oxide particular reduces the work function and the activation energy

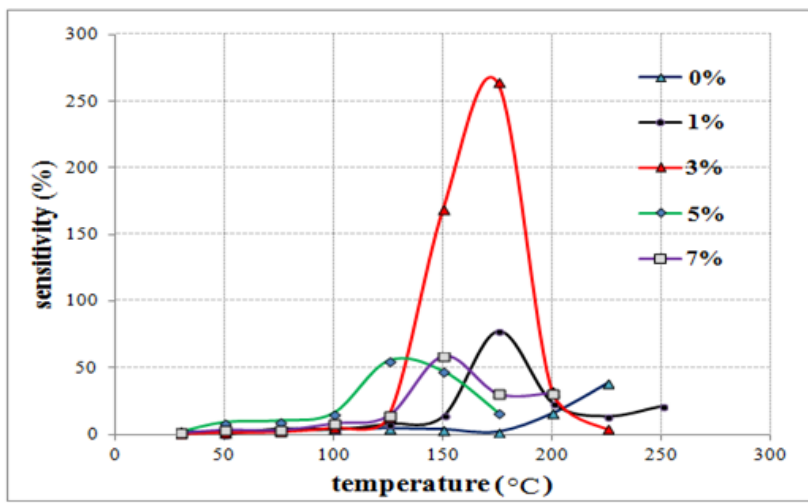

Figure 4: The variation of sensitivity with the operating temperature of the undoped and doped $\mathrm{CdO}$ (Pure , $1 \%, 3 \%, 5 \%, 7 \%$ ) for mixing ratio $3 \%$ (NO :air), and bias voltage of $5 \mathrm{~V}$ on $\mathrm{Al}_{2} \mathrm{O}_{3}$ substrate. 


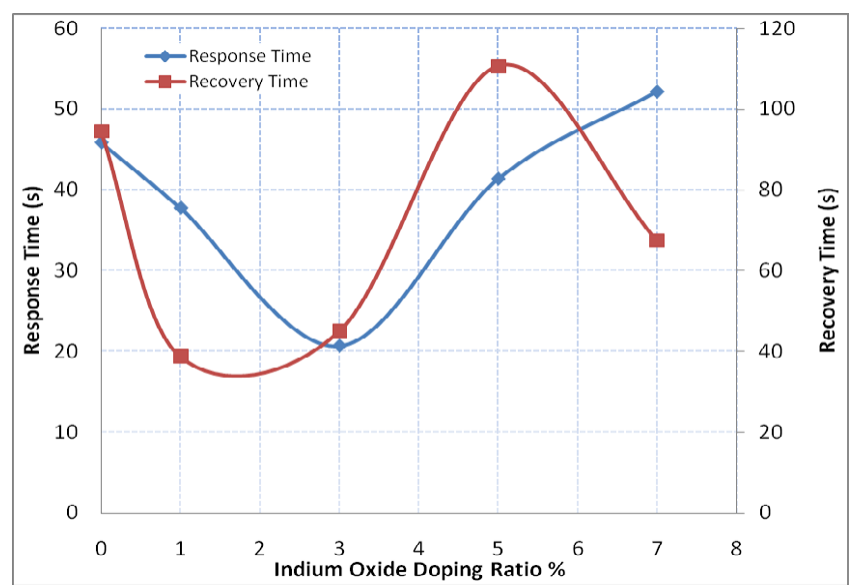

Figure 5: The variation of Response time and Recovery time with Indium Oxide doping ratio on quartz substrate at optimum operating temperature.

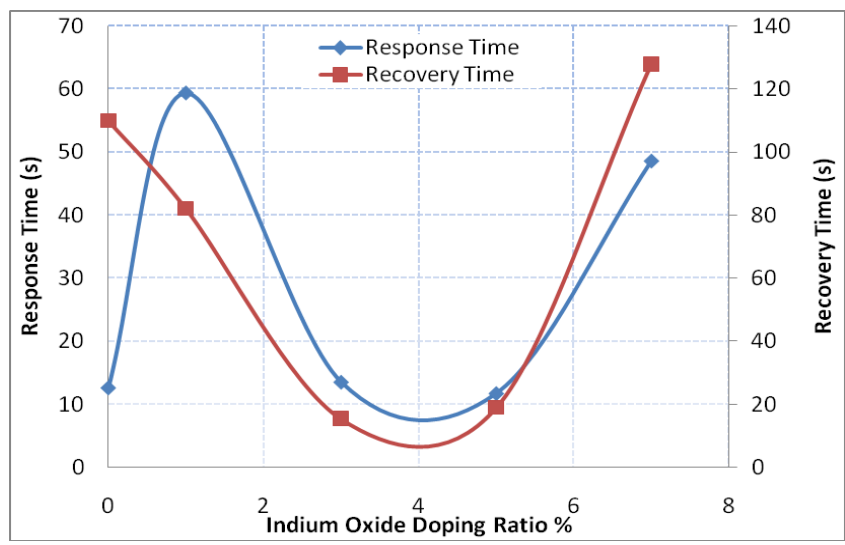

Figure 6: The variation of Response time and Recovery time with Indium Oxide doping ratio on sapphire $\alpha-\mathrm{Al}_{2} \mathrm{O}_{3}$ substrate at optimum operating temperature.

of surface reaction, may be associated with an increase in oxygen vacancies created upon $\operatorname{In}_{2} \mathrm{O}_{3}$ doped $\mathrm{CdO}$ lattice. Besides that, ions of indium occupy energy level below conduction band and behave as an activator, consequently electrons move easily move to conduction band, so that the resistance of thin film reduce [24]. The increased adsorption of oxygen on the surface extracts conduction electrons from the near surface region forming an electron depleted surface layer. That increased number of active adsorption sites and achieved fast response time for sensors. In general the response time decreased when increased the doping ratio of indium to optimum doping ratio and the response time increased with increasing indium doping ratio as shown in figures. In real situations a fast response time is usually required, but a fast recovery time is not so important, and recovery time decreases above optimal time with increases temperature.

\section{Grain size effect on sensitivity}

Figures 7 and 8 are shown The variation of surface grain size and sensitivity with Indium Oxide doping ratio of optimum operating temperature for undoped and doped $\mathrm{CdO}$ for $3 \% \mathrm{NO}_{2}$ :air mixing ratio and bias voltage of $5 \mathrm{~V}$ for quartz and $\mathrm{Al}_{2} \mathrm{O}_{3}$ substrates. Figure 7 reveals that the decrease of the particle size with $\mathrm{In}_{2} \mathrm{O}_{3}$ doping concentration and (1\% doping) ratio with grain size $(90.44 \mathrm{~nm})$ has the maximum sensitivity among other samples for quartz substrate. While the samples deposited on $\mathrm{Al}_{2} \mathrm{O}_{3}$ substrate, the maximum sensitivity shows with grain size $(92.42 \mathrm{~nm})$ at (3\% doping) as shown in Figure 8 .

One of the possible reasons for reduction in optimal temperature may be related to the reduction in the particle size [25]. The reduction in the grain size allows the space charge to cover large volume of the grain and the large number of grain boundaries providing large area for adsorption $\mathrm{O}^{-} \mathrm{O}^{-2} \mathrm{Hence} \mathrm{large} \mathrm{variation} \mathrm{in} \mathrm{the} \mathrm{barrier} \mathrm{and} \mathrm{resistance} \mathrm{can}$ enhance the reactivity at lower temperature. Also, the density of surface states increases with reduction in the particle size hence, the density of surface states can help in lowering the operating temperature. The other possibility may be the Fermi level pinning, which may reduce with doping. The Fermi level pinning, can help in lowering the temperature and also can lead to large variation in surface barrier and, hence the resistance. This may also be the reason for the higher sensitivity with small size particles. Doping with indium oxide increases this disorder, as well as creating more oxygen vacancies for material transport during material synthesis is usually expected the lower activation energies experienced by samples doped at $3 \%$ indium oxide. At low doping concentrations, high disorder and oxygen vacancy concentrations likely outweigh this effect at very small grain sizes. However, this also depends on the relation of particle size with the width of depletion layer, known as Debye length. When the particle/grain is smaller than

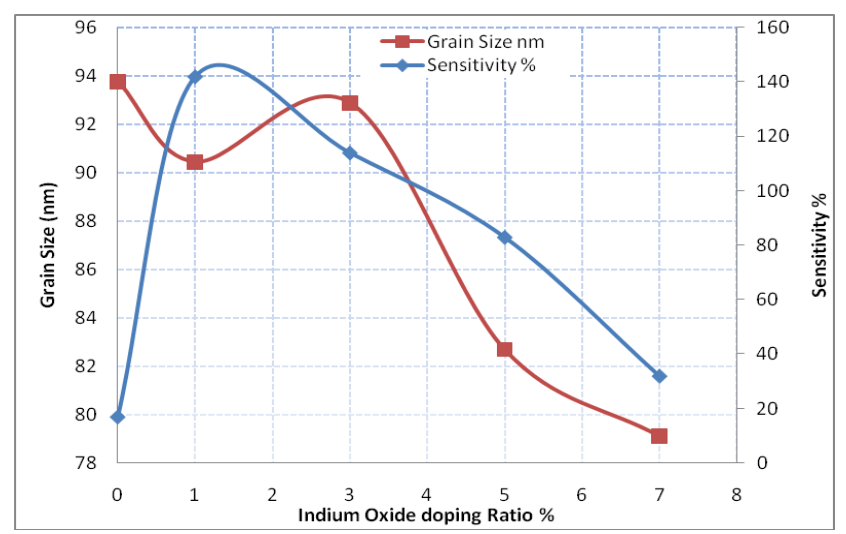

Figure 7: The variation of grain size and sensitivity with Indium Oxide doping ratio at optimum operating temperature for quartz substrate.

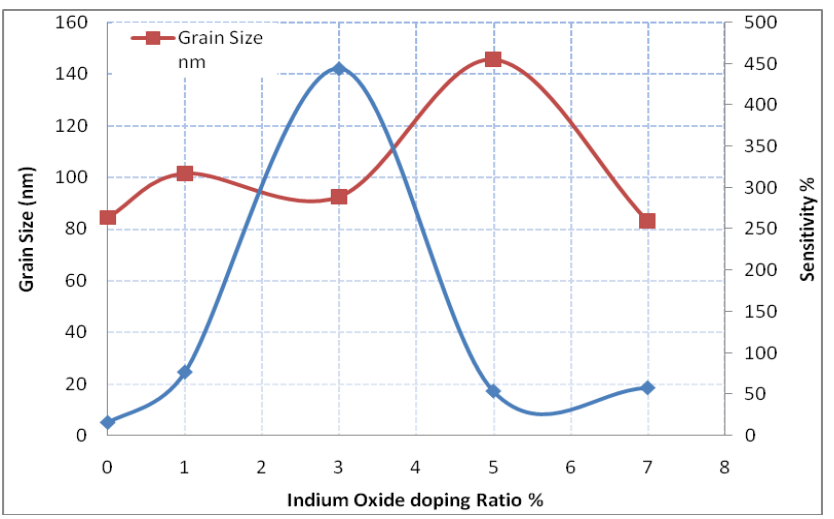

Figure 8: The variation of grain size and sensitivity with Indium Oxide doping ratio at optimum operating temperature for $\mathrm{Al}_{2} \mathrm{O}_{3}$ substrate. 


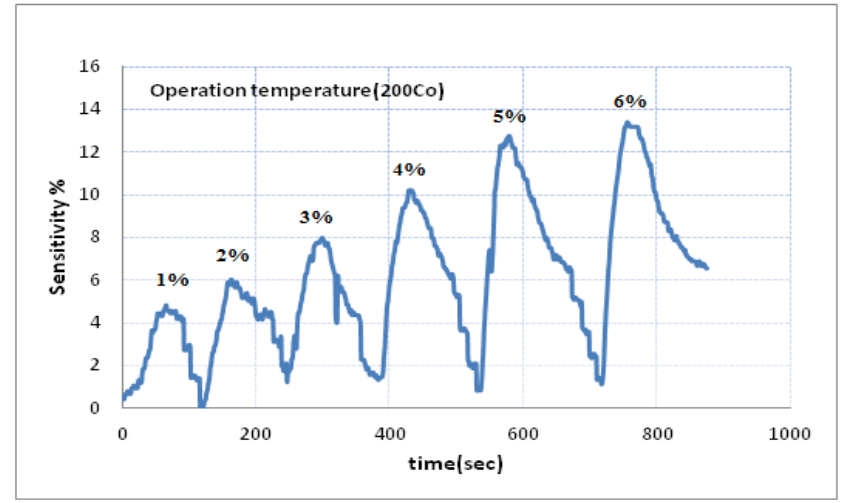

Figure 9: The variation of Sensitivity with time for different Concentration with $\mathrm{NO}_{2}$ : Air mixing ratio of $\mathrm{CdO}$ for quartz substrate at bias voltage of $5 \mathrm{~V}$ and operating temperature $\left(200^{\circ} \mathrm{C}\right)$.

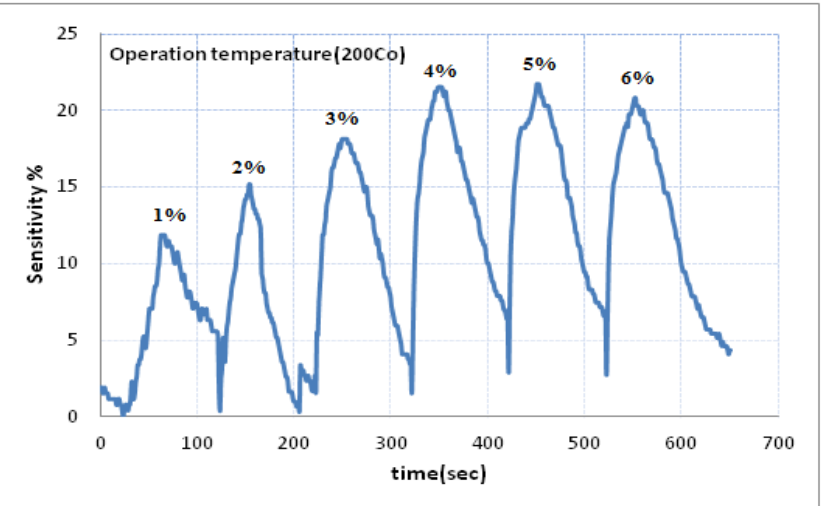

Figure 10: The variation of Sensitivity with time for different Concentration with $\mathrm{NO}_{2}$ : Air mixing ratio of $\mathrm{CdO}$ for sapphire $\alpha-\mathrm{Al}_{2} \mathrm{O}_{3}$ substrate at bias voltage of 5 $\checkmark$ and operating temperature $\left(200^{\circ} \mathrm{C}\right)$

the Debye length, the sensitivity will be much higher than that of the grains having size larger than Debye length [22].

\section{The influence of gas concentration on sensitivity}

The gas sensing characteristics of the CdO film are carried out for $\mathrm{NO}_{2}$ oxidizing gas at different mixing ratios. A known amount of target gas is introduced after the Ohmic resistance of the sensor material gets stabilized. The recovery characteristics (when the target gas is withdrawn) are also monitored as a function of time. Figures 9 and 10 demonstrates sensor test at $5 \mathrm{~V}$ bias voltage and operating temperature of $200^{\circ} \mathrm{C}$. The Nitrogen Dioxide: air mixing ratio is set at $1 \%, 2 \%, 3 \%$, $4 \%, 5 \%$ and $6 \%$ respectively for quartz and sapphire $\alpha-\mathrm{Al}_{2} \mathrm{O}_{3}$ substrates. The CdO sensing samples are prepared for different conditions.

These figures exhibit the sensitivity as a function of $\mathrm{NO}_{2}$ gas concentration for the $\mathrm{CdO}$ sensing element at $200^{\circ} \mathrm{C}$. The sensitivity of the $\mathrm{CdO}$ gas sensor increases as the $\mathrm{NO}_{2}$ gas concentration is increased from $1 \%$ to $6 \%$ and it drops relatively rapidly when the $\mathrm{NO}_{2}$ gas is removed, indicating that the gas sensor has a good response for different $\mathrm{NO}_{2}$ concentrations. Besides, it takes almost the same time for the sensor to reach the maximum sensitivity for different $\mathrm{NO}_{2}$ concentrations. The CdO gas sensor have quartz substrate, The sensitivity increases as the $\mathrm{NO}_{2}$ gas concentration is increased from $1 \%$ to $5 \%$ and it have saturation sensitivity at $5 \%$ to $6 \%$ at $\mathrm{NO}_{2}$ gas concentrations and same behavior for $\mathrm{CdO}$ gas sensor have $\mathrm{Al}_{2} \mathrm{O}_{3}$ substrate with $4 \%$ saturation $\mathrm{NO}_{2}$ gas concentration. This result is consistent with the conclusion for the dominance of operation temperature for the response time [26]. Both response and recovery time of the sensor have the same behavior as the $\mathrm{NO}_{2}$ target gas concentration increases. Both of them were decreased with increasing $\mathrm{NO}_{2}$ concentration up to $6 \%$ at which the lowest response and recovery times of 17.1 and $82.8 \mathrm{~s}$ for sapphire $\alpha-\mathrm{Al}_{2} \mathrm{O}_{3}$ substrate and lowest response and recovery times of $31.5 \mathrm{~s}$ and $68.4 \mathrm{~s}$ for quartz substrate are observed. As it is apparent from the figures, the sensor sensitivity to $\mathrm{NO}_{2}$ gas was increases linearly with $\mathrm{NO}_{2}$ test gas mixing ratio up to $6 \%$.

\section{Conclusions}

In this work, we have successfully prepared undoped and doped $\mathrm{CdO}$ with different concentration of $\operatorname{In}_{2} \mathrm{O}_{3}$ nanofilms on quartz and sapphire $\mathrm{a}-\mathrm{Al}_{2} \mathrm{O}_{3}$ substrates by Pulse laser deposition method.

The AFM images of all samples are displayed granular structure. The granular films show higher surface area. The grains sizes are decrease with increasing of doping concentration ratio of $\operatorname{In}_{2} \mathrm{O}_{3}$, and small grain size achieves at (7\%) doping ratio for quartz and sapphire a- $\mathrm{Al}_{2} \mathrm{O}_{3}$ substrate.

The gas sensitivity tests for undoped and doped CdO samples that working at elevated temperature, The sensitivity of the pure $\mathrm{CdO}$ film to $\mathrm{NO}_{2}$ gas was began at $100^{\circ} \mathrm{C}$ and the maximum sensitivity at 200 $225^{\circ} \mathrm{C}$. The sensitivity for $\operatorname{In}_{2} \mathrm{O}_{3}$ doped $\mathrm{CdO}$ was began at $50^{\circ} \mathrm{C}$. The high sensitivity and fast response time is achieve for (1 wt\%) doping concentration and (1-3\%) doping concentration for film deposited on quartz and sapphire $\alpha-\mathrm{Al}_{2} \mathrm{O}_{3}$ substrate respectively. The sensitivity of samples was decreasing when increasing of doping level. The interest of doping is to reduce the operating temperature sensor and increase of speed of response time.

\section{References}

1. Kamal H (2005) The electrochromic behavior of nickel oxide films sprayed at different preparative conditions. Thin solid films 483: 330-339.

2. lacomi $F$ (2006) Physical characterization of CdMnS nanocrystalline thin films grown by vacuum thermal evaporation. Journal of optoelectronics and advanced material 8: 266.

3. Patil PS (1999) Versatility of chemical spray pyrolysis technique. Material Chemistry and Physics 59: 185

4. Ortega M, Santana G, Morales-Acevedo A (2000) Optoelectronic properties of $\mathrm{CdO} / \mathrm{Si}$ photodetectors. Solid State Electron 44: 1765-1769.

5. Ferro R, Rodriguez JA (2000) Influence of F-doping on the transmittance and electron affinity of $\mathrm{CdO}$ thin films suitable for solar cells technology. Sol Energy Matter Sol Cells 64: 363-370.

6. Suhail MH, Ibrahim IM, Mohan Rao G (2012) Characterization and gas sensitivity of cadmium oxide thin films prepared by thermal evaporation technique. Journal of Electron Devices 13: 965.

7. Vigil O, Cruz F, Morles-Acevedo A, Contreras-Puene G, Vaillant L (2001) Structural and optical properties of annealed $\mathrm{CdO}$ thin films prepared by spray pyrolysis. Matter Chem Phys 68: 249-252.

8. Subramanyam TK, Uthanna S, Srinivasulu Naidu B (1998) Preparation and characterization of $\mathrm{CdO}$ films deposited by dc magnetron reactive sputtering Materials Letters 35: 214-220.

9. Hobert H, Seltmann B (1996) Infrared study of SiO2/TiO2/CdO layers on glass prepared by the sol-gel method. Journal of Non-Crystalline Solids 195: 54-63.

10. Tadjarodi A, Imani M (2011) Synthesis and characterization of CdO nanocrystalline structure by mechanochemical method. Materials Letters 65: 1025-1027. 
Citation: Yousif AA, Hasan MH (2015) Gas Sensitivity and Morphologically Characterized of Nanostructure CdO Doped $\operatorname{In}_{2} \mathrm{O}_{3}$ Films Deposited by Pulsed Laser Deposition. J Biosens Bioelectron 6: 192. doi:10.4172/2155-6210.1000192

11. Ambia MG, Eslam MN, Hakim MO (1992) Temperature effects on the electrical properties of $\mathrm{ZnO}$ thin films prepared by the pyrosol process. Sol Energy Mat Sol Cells 28: 103-111.

12. Mohamed HA, Ali HM (2008) Characterization of ITO/CdO/glass thin films evaporated by electron beam technique. Journal of Science Technology Advanced Material 9: 025016

13. Mahaboob Beevia M, Anusuyab M, Saravananc V (2010) Characterization of CdO thin films prepared by SILAR deposition technique. International Journal of Chemical Engineering and Applications 1: 151.

14. Bari RH, Pati SB (2014) Nanostructured CdO thin films for LPG and $\mathrm{CO}_{2}$ gas sensor prepared by spray pyrolisis technique. International Letters of Chemistry, Physics and Astronomy 18: 31-46.

15. Pan LL, Li GY, Lian GS (2013) Structural, optical and electrical properties of cerium and gadolinium doped CdO thin films. Appl Surf Sci 274: 365-370.

16. Zheng BJ, Lian JS, Zhao L, Jiang Q (2010) Optical and electrical properties of In-doped $\mathrm{CdO}$ thin films fabricated by pulse laser deposition. Appl Surf Sci 256: 2910-2914.

17. Karunagaran B, Uthirakumar $\mathrm{P}$, Chung SJ, Velumani S, Suh EK (2007) $\mathrm{TiO}_{2}$ thin film gas sensor for monitoring ammonia. Mater Charact 58: 680-684.
18. Liewhiran C, Phanichphant S (2007) "Influence of Thickness on Ethanol Sensing Characteristics of Doctor-bladed Thick Film from Flame-made $\mathrm{ZnO}$ Nanoparticles." Sensors 7: 185-201.

19. Korotcenkov G (2007) Metal oxides for solid-state gas sensors: What determines our choice? Mater Sci Eng B Solid-State Mater Adv Technol 139 $1-23$.

20. (2010) Laser and O. Technique, Structure, no. June.

21. Ansari ZA, Ko TG (2005) IEEE Sens J 5: 5.

22. Mizsei (1995) How can sensitive and selective semiconductor gas sensors be made? Sensors Actuators B Chem 2-3: 173-176.

23. Garde S (2010) Sensors \& Transducers 122: 128-142.

24. Sujitno T, Sudjatmoko S (2006) Atom Andonesia 32: 65-79.

25. Kawar SS (2012) IJCPS 1: 11-14

26. Ismail YA, Md Yusuf MN, Wan Shamsuri MN, Wahab Y, Othaman Z (2006) Ibnu Sina Institute for Fundamental Science Studies, UTM. 